\title{
In vivo site-specific recombination using the $\beta$-rec/six system
}

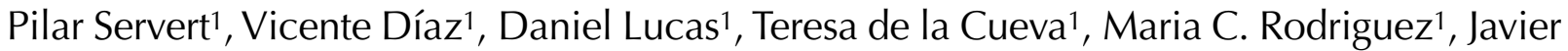 \\ García-Castro1', Juan C. Alonso², Carlos Martínez-A1', Manuel A. González1,3, and Antonio Bernad11,3
}

BioTechniques 45:69-78 (July 2008)

doi 10.2144/000112826

\begin{abstract}
The prokaryotic $\beta$ serine recombinase ( $\beta$-rec) catalyzes site-specific recombination between two directly oriented six sites (93 bp) in mammalian cells, both in episomal and in chromosomally integrated substrates. The $\beta$-rec/six exclusive intramolecular site-specific recombination (SSR) system has been proposed as a suitable approach when several independently controlled recombination events are needed in a single cell. Here we explored the use of the $\beta$-rec/six system for selective induction of genome-targeted modifications. We generated and analyzed mouse transgenic lines $(\mathrm{Tg} \beta)$ expressing $\beta$-rec under the control of the Lck promoter. $\beta$-rec activity was demonstrated, and there was no evidence of alterations to thymic or peripheral T cell development. We developed two transgenic mouse lines harboring different target sequences (Tgrec and KOsix) and analyzed the effect of $\beta$-rec expression on these animals. The results indicate that the $\beta$-rec/six SSR system is functional for in vivo gene-targeting applications.
\end{abstract}

\section{INTRODUCTION}

Site-specific recombinases are the most important tool for conditional gene targeting (1-3). Commonly used enzymes that catalyze site-specific recombination (SSR) fall into two categories, based on evolutionary and mechanistic relatedness: the tyrosine recombinases and the serine recombinases (reviewed in Reference 4). Tyrosine recombinases (e.g., $\lambda$-Int, Cre, Flp) can catalyze integration and/or excision (4). Serine recombinases are subdivided into the small serine recombinases, which catalyze only intramolecular strand exchange (excision and/or inversion), and the large serine recombinases, which catalyze both inter- and intramolecular strand exchange (integration and excision) (5).

The small $\beta$ serine recombinase ( $\beta$ rec) from plasmid pSM19035 catalyzes SSR in mammalian cells, both in episomal plasmids and in chromosomally integrated substrate structures (6). To delete the target sequence, $\beta$-rec requires a supercoiled substrate and chromatin-associated protein (e.g., bacterial Hbsu or eukaryotic HMG1 proteins) $(7,8)$, which can be provided by the mammalian cell environment (6). The $\beta$-rec SSR system that uses the six recognition sequence (9) is termed $\beta$-rec/six (10).

Current systems for conditional gene targeting (reviewed in Reference 11) allow spatio-temporal control of the genetic modification event, overcoming some limitations of classical targeting systems such as embryonic lethality or compensation mechanisms $(12,13)$. Cre-loxP is the most widely used SSR system $(1,14)$, and tissue-specific and conditional gene-targeting events are reported in a wide variety of tissues and organs (15-18). Although the utility of these systems is unquestionable, to date only Cre-loxP and, to a lesser extent, the Flp/FRT and Int/attP SSR systems (19-21) are used in vivo. The phage phiC31- and phiBT1-encoded large serine recombinases integrate expression constructs flanked by their respective specific recognition sites (attB) into genomic pseudo-attP sites (22); this model has been used for complete and persistent phenotypic correction in phenylketonuric mice
(21), the tyrosinemia type I mouse model (22), and keratinocytes from epidermolysis bullosa patients $(21,22)$.

Controlled induction of SSR is clearly advantageous. Lineage-specific expression of the recombinase provides a first level of control. A second level is obtained by using an inducible promoter, or by fusing the recombinase to a protein module that retains it in the cytoplasm until interaction with inductor molecules translocates the fusion protein to the nucleus (23). The fusion method has been applied to the Cre-loxP and Flp-FRT systems, using the ligand binding domain (LBD) of the sex steroid nuclear receptors (11), and the androgen receptor LBD has recently been used in the $\beta$-rec/six model (24). The combined use of these systems remains limited $(25,26)$, and therefore characterization of site-specific recombinases that could function as alternatives to or in combination with existing systems would be of interest.

We evaluated a $\beta$-rec-dependent recombination-activated gene expression (RAGE) system, consisting of the lac $Z$ reporter gene separated by a sixed puromycin resistance gene

\footnotetext{
${ }^{1}$ Departamento de Inmunología y Oncología, ${ }^{2}$ Departamento de Biotecnología Microbiana, Centro Nacional de Biotecnología, Spanish National Research Council (CSIC), Campus Universidad Autónoma de Madrid, and ${ }^{3}$ Department of Regenerative Cardiology, Centro Nacional de Investigaciones Cardiovasculares (CNIC), Madrid, Spain
} 


\section{Research Reports}

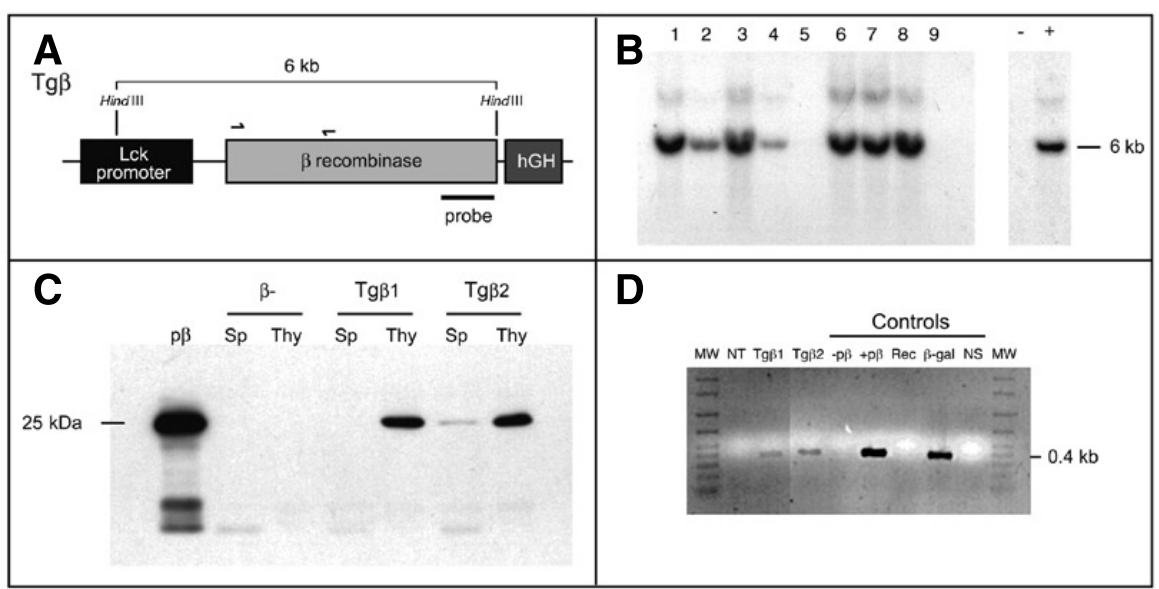

Figure 1. Generation and characterization of mouse transgenic lines expressing $\beta$ recombinase. (A) Scheme of the Lck- $\beta$-rec construct used to obtain transgenic lines $\operatorname{Tg} \beta)$ in which the $\beta$-rec open reading frame is under the control of the proximal Lck promoter; hGH indicates the human growth hormone polyadenylation signal. Positions of the sequences used as a Southern blot probe (bar), HindIII restriction sites, and PCR oligonucleotide primers (arrows) are indicated. (B) Genomic DNA from nine mice (1-9), digested with HindIII, was analyzed by Southern blot using the probe indicated in (A). Positive $(+)$ and negative (-) controls for detection of the specific fragment $(6 \mathrm{~kb})$ are shown. Mice $1,3,6,7$, and 8 were used to establish five transgenic lines, which were named $\operatorname{Tg} \beta 1, \operatorname{Tg} \beta 2, \operatorname{Tg} \beta 3, \operatorname{Tg} \beta 4$, and $\operatorname{Tg} \beta 5$, respectively. (C) Crude spleen (Sp) and thymus (Thy) extracts $(20 \mu \mathrm{g})$ from transgenic lines $\operatorname{Tg} \beta 1$ and $\operatorname{Tg} \beta 2$ and nontransgenic mice ( $\beta$-) were analyzed by Western blot for $\beta$-rec protein; a positive control of $5 \mathrm{ng}$ purified recombinant $\beta$-rec protein was included (p $\beta$ ). (D) To evaluate active $\beta$-rec protein, crude thymus extracts from transgenic lines $\operatorname{Tg} \beta 1$ and $\operatorname{Tg} \beta 2$ and nontransgenic mice $(\beta$-) were tested using the $\beta$-rec/six RAGE system with the Recombiner substrate plasmid. After RAGE, resulting plasmids were analyzed by PCR to detect the expected fragment $(0.4 \mathrm{~kb})$. Positive ( $\mathrm{p} \beta$, including $\beta$-rec purified protein) and negative (-p $\beta$, lacking $\beta$-rec protein) recombination controls were included, as well as positive ( $\beta$ gal, containing an in vitro recombined plasmid derived from Recombiner), negative (Rec, Recombiner plasmid), and no substrate plasmid (NS) PCR controls. MW, molecular weight markers.

(Puro $^{\mathrm{R}}$ ) (flanked by six sites in direct orientation) (27). The $\beta$-RAGE system also works efficiently with a $\beta$-rec fused through its $\mathrm{C}$-terminal to green fluorescent protein ( $\beta$-EGFP) (24). As with Cre-loxP (28), combination of these two approaches resulted in a simple, rapid way to enrich cell clones that have undergone recombination after transient $\beta$-EGFP expression, using fluorescence-activated cell sorting (FACS) (24).

The exclusively intramolecular recombination capacity of the $\beta$-rec/six system (10) suggested that it might be an appropriate approach when several independently controlled recombination events are required (6). This would prevent intermolecular recombination events between remaining recombination sites, which can occur with other recombinases. The $\beta$-rec/ six system, combined with Cre- and/ or Flp-based SSR systems, would expand possibilities for programmed modification of eukaryotic genomes in complex spatio-temporal combinations. Here we explore the use of the $\beta$-rec/six system for selective induction of in vivo gene targeting.

\section{MATERIALS AND METHODS}

\section{Plasmids and Cloning}

To facilitate description of the different constructs and transgenic animal models generated, we have included a list of abbreviations used in the manuscript (Supplementary Table S1 available online at www. BioTechniques.com). Supplementary Table S2 summarizes the main characteristics of plasmids pSV $\beta 2$ (6), pLck-hGH (29), and pßEGFP (24), and of the retroviral vector pLZR$\beta$-EGFP (encoding the $\beta$-rec-EGFP fusion protein), the control vector pLZR-CMV-EGFP, and the substrate Recombiner plasmid $(24,27)$. Plasmid pGEM-E-560-R-LNL (30), containing both homology arms of the TCR $\beta$ targeting vector, was provided by Dr. P. Ferrier (Marseille, France). Plasmid pLck- $\beta$ was constructed by subcloning the $\beta$-rec open reading frame (ORF) from pSV $\beta 2$ into the parental vector pLck-hGH; two independent clones were sequenced and tested in Jurkat cells for $\beta$-rec expression by Western blot and $\beta$-rec-dependent RAGE (27). The pLck-rec plasmid was obtained after subcloning a Sse8387I-SgrAI fragment, from the Recombiner plasmid (27) containing the sixed reporter construct, into the parental pLck-hGH vector. The sequence of the six site used was TTATAGGTCAATAGAGTATACT TATTTGTCCTATTGATTAGATAGC AGTATAATAGCTTTATAGAGTAGG TCATTTAAGTTGAGCATAATAGG. Two independent clones were partially sequenced and tested by $\beta$-recdependent RAGE. After pLck-rec plasmid transfection in Jurkat cells, we tested pLck-rec recombination after retroviral-driven expression of $\beta$-EGFP.

The psix-neo-sixTCR $\beta$ plasmid is based on the pGEM-E-560-R-LNL construct containing homology arms (TCR $\beta 1$ and TCR $\beta 2$ ) corresponding to the TCR $\beta$ gene (30). Both arms of the new targeting vector were PCRamplified from the pGEM-E-560-RLNL plasmid using the Expand Long Template PCR kit (Roche, Mannheim, Germany) and the following primers (sequences in Supplementary Table $\mathrm{S} 3)$ : (i) for the short arm (TCR $\beta 2$; $1.1 \mathrm{~kb})$, TCRb2s and TCRb2as, both including a unique $A s c$ I site; (ii) for the long arm (TCR $\beta 1 ; 2.8 \mathrm{~kb})$, LTCRBS, which introduces a $F s e$ restriction site, and TCRb1as, which contains a unique PmeI restriction site. Cycling conditions were $94^{\circ} \mathrm{C}$ for $2 \mathrm{~min} ; 30$ cycles of $94^{\circ} \mathrm{C}$ for $10 \mathrm{~s}, 60^{\circ} \mathrm{C}$ for $30 \mathrm{~s}$ and $68^{\circ} \mathrm{C}$ for $2 \mathrm{~s} ; 68^{\circ} \mathrm{C}$ for $7 \mathrm{~min}$. Fragments were cloned in the PTA-cloning vector PCR 2.1 (Invitrogen, Barcelona, Spain) and verified by enzymatic restriction and sequencing.

For the psix-neo-sixTCR $\beta$ (psixTCR $\beta$ ) targeting vector, we generated a basic skeleton, termed pUC-NP. Into this vector we cloned a linker obtained by hybridizing the oligonucleotides PUC-NPas and PUC-NPs to generate restriction sites. 


\section{Research Reports}

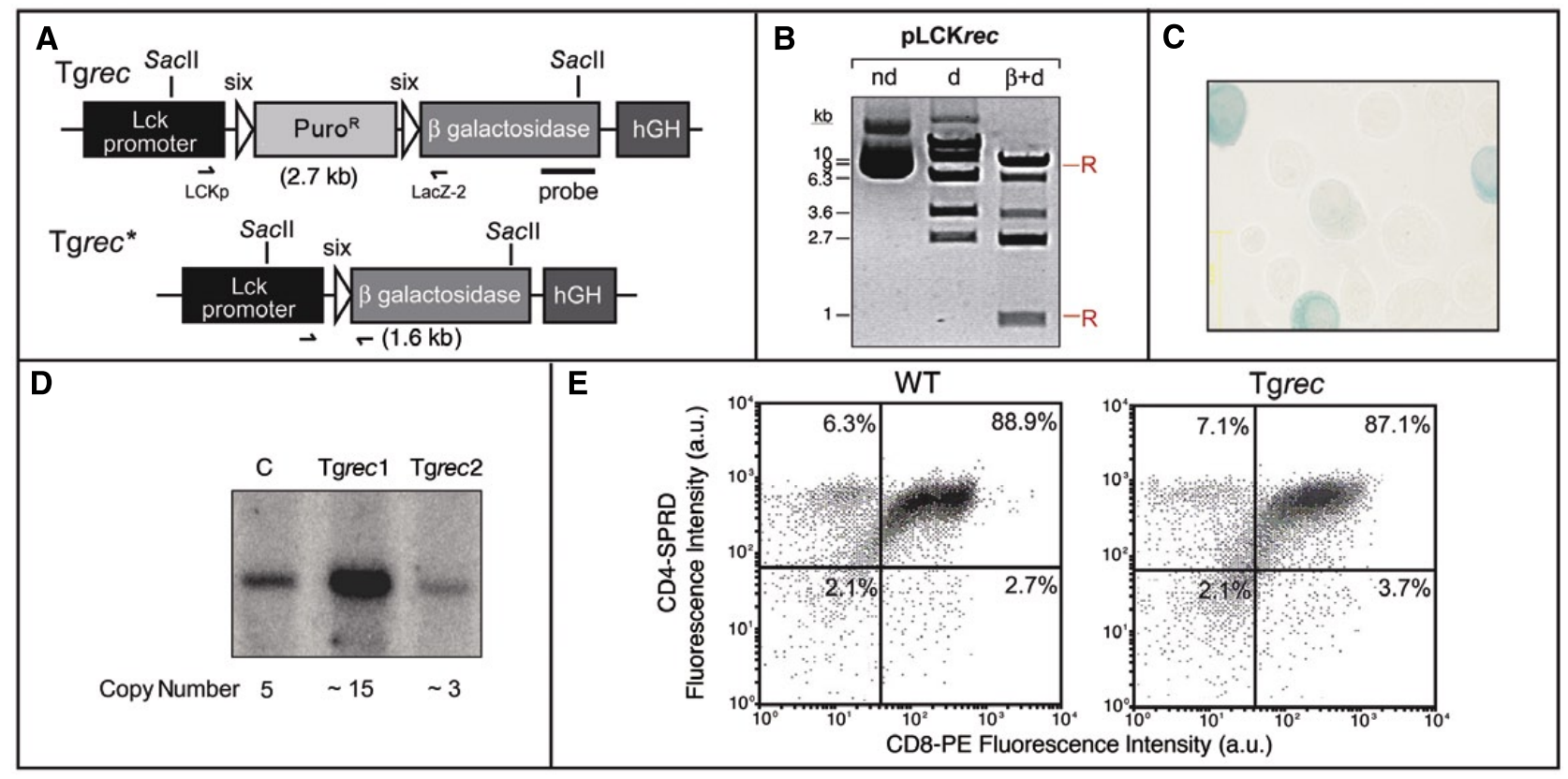

Figure 2. Generation of transgenic mouse lines harboring substrates for RAGE analysis of $\boldsymbol{\beta}$ recombinase activity. (A) Scheme of the Lck-rec reporter construct used to generate Tgrec transgenic lines, in which the puromycin resistance open reading frame (ORF) (Puro ${ }^{\mathrm{R}}$ ), flanked by six sequences (sixed) is under the control of the proximal Lck promoter and followed by the LacZ ORF; hGH indicates the human growth hormone polyadenylation signal. Positions of the sequences used as a probe for Southern blot (bar) and PCR oligonucleotide primers (arrows; LCKp and LacZ-2) are indicated. The lower scheme shows the structure of the Tgrec construct after $\beta$-rec/six recombination (Tgrec*). (B) Evaluation of the ability of the Lck-rec reporter construct (pLck-rec) to support $\beta$-rec/six recombination reactions. The Lck-rec reporter construct (pLck-rec) used to generate the transgenic mouse lines was used in an in vitro reaction of the $\beta$-rec/six RAGE system; resulting plasmid mixtures were SacII-digested, and the restriction fragments fractionated by electrophoresis. The nonrecombined plasmid generated four restriction fragments of $10,6.3,3.6$, and $2.7 \mathrm{~kb}$ (lane $\mathrm{d}$; a non-labeled larger, faint $12.7 \mathrm{~kb}$ band corresponding to linearized plasmid also appears), whereas recombined plasmids generate the three smaller fragments plus two specific (diagnostic) fragments (R; 9 and $1 \mathrm{~kb}$ ). nd, nondigested construct; d, SacII-digested; $\beta+$ d, recombined and SacII-digested. (C) After RAGE, the mixture of recombined constructs was electroporated into Jurkat cells and cultures were analyzed after $48 \mathrm{~h}$ for $\beta$-galactosidase staining (blue cells). (D) After generating two transgenic lines (Tgrec 1 and Tgrec 2 ), copy number was estimated in each by Southern blot of NcoI- and EcoRV-digested genomic DNA, using the specific probe from the pLck-rec plasmid indicated in (A). A positive control (+) containing five copies/genome of the target sequence was used for reference. (E) Thymus, spleen, and peripheral blood cell subpopulations from wild-type (WT) and Tgrec mouse lines were tested by FACS to confirm absence of undesired effects of the integrated transgenic constructs; the panel shows representative $\mathrm{CD} 4 / \mathrm{CD} 8$ thymic subpopulations. a.u., arbitrary units.

The two six site-containing fragments (obtained from the Recombiner plasmid) were cloned sequentially, first in the XbaI/HindIII sites and then Bam HI/SpeI, to obtain pUC-six2. Into this plasmid we sequentially cloned the neomycin resistance cassette from pGKneobpA (in XhoI/EcoRI), the thymidine kinase (TK) negative selection marker (NotI/FseI), and the two homology arms (TCR $\beta 2$, AscI/ PacI sites; TCR $\beta 1$, FseI/PmeI). The vector was tested by restriction analysis and partial sequencing, and tested as a substrate for $\beta$-rec-dependent RAGE.

\section{Cell Culture, Transfections, and Retroviral Transduction}

Jurkat and peripheral $\mathrm{T}$ cells were cultured in RPMI 1640 (Invitrogen) supplemented with $10 \%$ fetal calf serum
(FCS; Invitrogen), $2 \mathrm{mM} \mathrm{L-glutamine,}$ $10 \mathrm{mM}$ HEPES, and $1 \mathrm{mM}$ sodium pyruvate (BioWhittaker, Walkersville, MD, USA). Cells were maintained at $10^{5}-10^{6}$ cells $/ \mathrm{mL}\left(37^{\circ} \mathrm{C}, 95 \%\right.$ humidity, $5 \% \mathrm{CO}_{2}$ ). To confirm plasmid function in Jurkat cells, plasmid DNA $(20 \mu \mathrm{g})$ was introduced by electroporation of $8 \times 10^{6}$ cells $(260 \mathrm{~V}, 960 \mu \mathrm{F}$; Gene Pulser, Bio-Rad, Hemel Hempstead, UK). After $48 \mathrm{~h}$, cells were selected by puromycin resistance or analyzed for $\beta$ galactosidase activity (23). Production of retroviral particles, retroviral transduction, and purification of transduced cells were as described (24).

\section{Mouse Models}

$\mathrm{C} 57 \mathrm{BL} / 6 \times \mathrm{CBA} / \mathrm{J}, \mathrm{CD} 1$, and C57BL/6 mice were obtained from Jackson Laboratories (Barharbor,
MN, USA), bred in our pathogenfree facility, and screened routinely according to the Federation of European Laboratory Animal Science Associations (FELASA) recommendations. All experiments were performed according to Spanish regulations (RD 233/88, MAPA) for the use and treatment of experimental animals, with the approval of the animal ethics committee.

Transgenic mice $(\mathrm{Tg})$ were obtained by pronucleus microinjection of fertilized oocytes $(\mathrm{C} 57 \mathrm{BL} / 6 \times \mathrm{CBA} / \mathrm{J})$ with $S a c$ II-linearized pLck- $\beta$ and pLckrec plasmids. Founders were identified by PCR and confirmed by Southern blot. PCR was conducted with oligonucleotides hGH-3 and hGH-4 $\left(95^{\circ} \mathrm{C}\right.$ for $2 \mathrm{~min} ; 35$ cycles of $95^{\circ} \mathrm{C}$ for $30 \mathrm{~s}, 60^{\circ} \mathrm{C}$ for $30 \mathrm{~s}, 72^{\circ} \mathrm{C}$ for $30 \mathrm{~s} ; 72^{\circ} \mathrm{C}$ for $7 \mathrm{~min}$ ), amplifying a $415 \mathrm{bp}$ band. The Southern 


\section{Research Reports}

probe for HindIII-digested genomic DNA was a 353 bp, HindIII/SauI fragment from pLck-rec. We obtained Lck- $\beta /$ Lck-rec double heterozygote transgenics $(\operatorname{Tg} \beta / \operatorname{Tgrec})$ by crossing single heterozygotes; offspring were screened by PCR using oligonucleotides LACUP and LACLO to detect the Lck$r e c$ transgene (729 bp fragment), and BETAs and BETAas to detect the Lck- $\beta$ transgene ( $600 \mathrm{bp}$ fragment $)\left(95^{\circ} \mathrm{C}\right.$ for 2 min; 35 cycles of $94^{\circ} \mathrm{C}$ for $30 \mathrm{~s}, 48^{\circ} \mathrm{C}$ for $30 \mathrm{~s}, 72^{\circ} \mathrm{C}$ for $2 \mathrm{~min} ; 72^{\circ} \mathrm{C}$ for $7 \mathrm{~min}$ ).

To obtain mice carrying a $\beta$-rec reporter substrate in a predetermined location, we used the psixTCR $\beta$ targeting vector to replace the TCR $\beta$ enhancer (E $\beta)$ locus with a sixed neomycin resistance gene. The psixTCR $\beta$ vector $(30 \mu \mathrm{g})$ was linearized with PacI and electroporation-transfected into ES cells (R1; $10^{7}$ cells; 250 $\mathrm{V}, 500 \mu \mathrm{F})$. Transfected cells were seeded on inactivated fibroblasts $(24 \mathrm{~h})$, then selected with G-418 $(300 \mu \mathrm{g} / \mathrm{mL})$ and gancyclovir $(2 \mu \mathrm{M})$. After seven days, resistant clones (576) were picked and cultured in $150 \mu \mathrm{g} / \mathrm{mL}$ G-418. Genomic DNA from individual clones was EcoRV-digested and Southern blot analyzed for homologous recombinant alleles, using as probe an EcoRV/SpeI fragment corresponding to the short arm (TCR $\beta 2$ ) of the targeting vector. Clones harboring the homologous recombinant allele were expanded, and chromosomal stability confirmed by karyotyping. Recombinant clones were selected after transfecting with $\mathrm{p} \beta E G F P$ to confirm that the homologous recombinant allele was a $\beta$-rec substrate. Clones were aggregated with $\mathrm{CD} 1$ blastocysts and chimeras obtained. From each chimera showing germ-line transmission, a homozygous mouse line was established and verified by PCR and Southern analysis. For PCR, we used the oligonucleotides TCRb1 and TCRb2g $\left(95^{\circ} \mathrm{C}\right.$ for $2 \mathrm{~min}$; 35 cycles of $94^{\circ} \mathrm{C}$ for $30 \mathrm{~s}$, $57^{\circ} \mathrm{C}$ for $30 \mathrm{~s}, 72^{\circ} \mathrm{C}$ for $2 \mathrm{~min} ; 72^{\circ} \mathrm{C}$ for $5 \mathrm{~min}$ ); bands corresponding to the homologous recombined allele $(1.22$ $\mathrm{kb})$ or the wild-type (WT) allele (600 bp) were detected.

\section{Southern Blot}

Genomic DNA $(10 \mu \mathrm{g})$ was enzymedigested overnight, followed by agarose

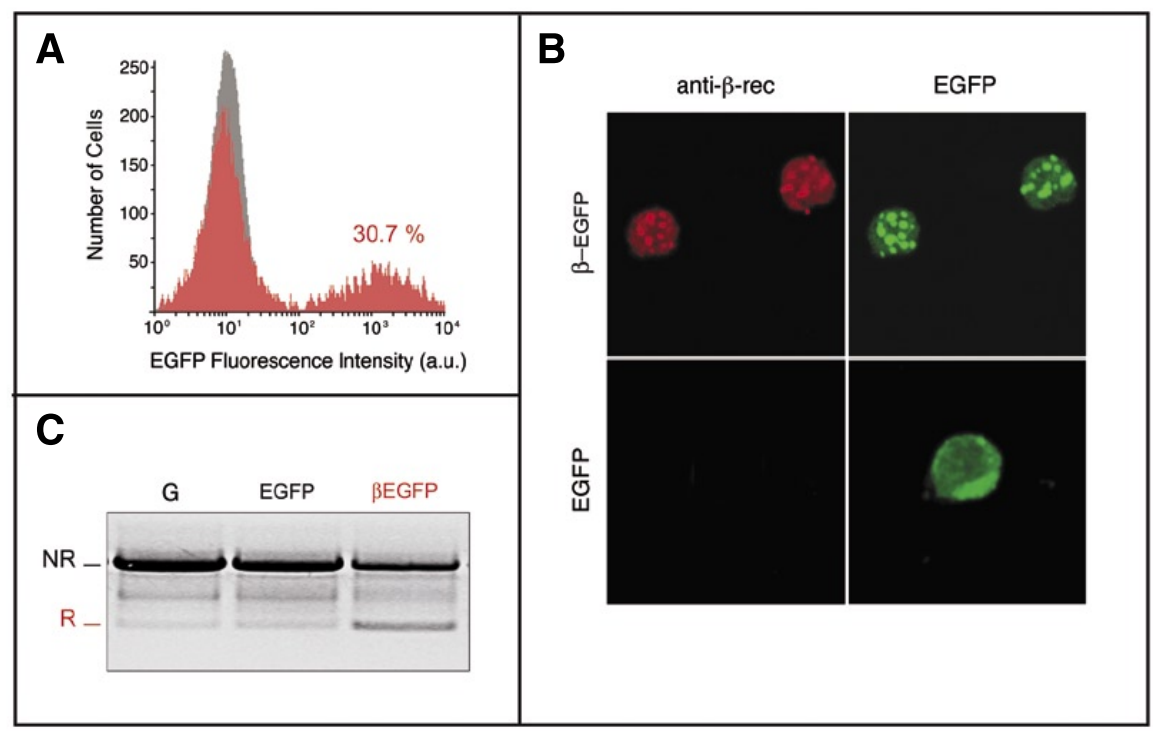

Figure 3. Functional evaluation of the $\beta$-rec/six system in vivo. (A) Peripheral $\mathrm{T}$ cells from Tgrec and wild-type (WT) mice were transduced with the pLZR- $\beta$-EGFP or pLZR-CMV-EGFP retroviral vectors for expression of $\beta$-EGFP fusion protein or EGFP marker, respectively. The figure shows a representative FACS analysis of transduced (red) and nontransduced (gray) transgenic peripheral $\mathrm{T}$ cells, in which $30.7 \%$ of peripheral $\mathrm{T}$ cells were retrovirally transduced $\left(\mathrm{EGFP}^{+}\right)$. a.u., arbitrary units. (B) Transduced cells $\left(\mathrm{EGFP}^{+}\right)$were purified by cell sorting, and expression of EGFP or $\beta$-EGFP fusion protein was monitored by fluorescence microscopy (EGFP, right panel, green). Anti- $\beta$-rec antibodies were used to specifically detect the $\beta$-EGFP fusion protein (anti$\beta$-rec, left panel, red). (C) Purified transduced cells (EGFP+) were analyzed by PCR using the LCKp/LacZ-2 oligonucleotide pair indicated in Figure 2A to detect the site-specific recombination (SSR)-diagnostic $(\mathrm{R}, 1.6 \mathrm{~kb})$ and nonrecombined $(\mathrm{NR}, 2.7 \mathrm{~kb})$ fragments. The figure shows results (corresponding to Tgrec 1 ) obtained with genomic DNA from tail (G) or peripheral T cells transduced with the pLZR-CMV-EGFP retroviral control vector (EGFP) or with the pLZR- $\beta$-EGFP retroviral vector $(\beta-\mathrm{EGFP})$.

gel fractionation and blotting onto nylon membranes (Hybond-N+). Filters were hybridized $\left(65^{\circ} \mathrm{C}\right)$ in Rapid-hyb buffer and specific hybridization probes were radiolabeled (Rediprime kit: GE Healthcare, Little Chalfont, UK).

\section{Primary Cell Suspensions and Purification of Specific Subpopulations}

Liver, brain, thymus, spleen, and mesenteric and peripheral lymph nodes (LN) were removed and disaggregated, erythrocytes lysed, and cells counted. Total $\mathrm{T}$ cell populations were purified (SpinSep; Stem Cell Technologies, Vancouver, BC, Canada). $\mathrm{T}$ cells were cultured $\left(48 \mathrm{~h}, 37^{\circ} \mathrm{C}\right)$ and activated by immobilized antiCD3 and anti-CD28 antibodies (BD Biosciences, Erembodegen, Belgium), followed by IL-2. Dead cells were removed (Ficoll gradient; NycoPrep, Nycomed Pharma, Asker, Norway). As required, we isolated double-negative (DN, CD4-/CD8-), single-positive (SP, $\mathrm{CD}^{+} / \mathrm{CD} 8-$ or $\mathrm{CD} 4 / \mathrm{CD}^{+}$), and double-positive (DP, $\left.\mathrm{CD}^{+} / \mathrm{CD}^{+}\right) \mathrm{T}$ cell subpopulations by FACS (EPICS Elite, Beckman Coulter, Fullerton, CA, USA) using CD3-FITC/CD4SPRD/CD8-PE triple staining (Southern Biotech, Birmingham, AL, USA). Crude extracts of specific subpopulations were prepared as described previously (24), and analyzed for $\beta$-rec/six activity or site-specific $\beta$-rec/six recombined products.

\section{In vitro $\beta$-rec/six RAGE}

To evaluate whether cell extracts or substrate constructs supported $\beta$-recdependent reactions, we used a RAGE system (27) adapted from previous in vitro prokaryotic $\beta$-rec/six systems $(31,32)$. Briefly, the sample ( $2 \mu \mathrm{g}$ total protein in $1 \mu \mathrm{l}$ ) was incubated with the plasmid of interest $(1 \mu \mathrm{g})$ in $25 \mu \mathrm{l}, 50$ 


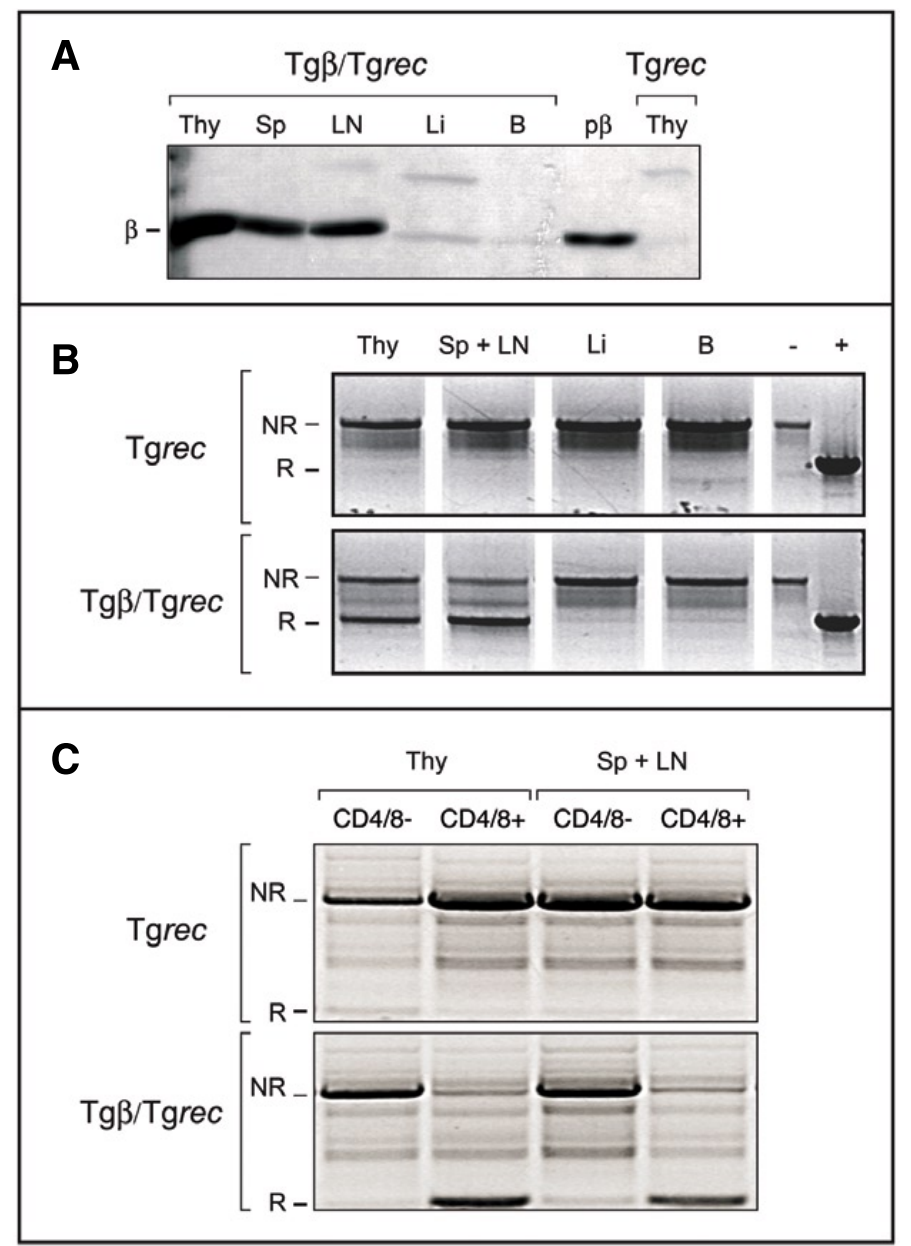

Figure 4. Analysis of $\beta$-rec/six recombination in double transgenic $\operatorname{Tg} \beta /$ Tgrec mice. (A) Western blot showing $\beta$ recombinase expression in protein extracts $(20 \mu \mathrm{g})$ from thymus (Thy), spleen (Sp), lymph nodes ( $\mathrm{LN}$ ), liver ( $\mathrm{Li})$, and brain (B) from $\mathrm{Tg} \beta / \mathrm{Tg} r e c$ mice, and thymus from Tgrec mice; $\mathrm{p} \beta$, purified recombinant $\beta$-rec protein (2 ng) used as positive control. (B) Genomic DNA from organs as in (A) was analyzed by PCR using the LCKp/LacZ-2 oligonucleotide pair to detect the site-specific recombination (SSR)-diagnostic (R, 1.6 kb) and nonrecombined (NR, $2.7 \mathrm{~kb})$ fragments; negative (-) and positive (+) controls were included. (C) Specific thymus (Thy) and spleen/lymph node ( $\mathrm{Sp}+\mathrm{LN})$ cell subpopulations from $\mathrm{Tg} \beta / \mathrm{Tg}$ rec mice were analyzed as in (B); CD4/8-, double-negative CD4-CD8- cells; CD4/8+, cells expressing $\mathrm{CD} 4, \mathrm{CD} 8$, or both.

$\mathrm{mM}$ Tris- $\mathrm{HCl}, \mathrm{pH} 7.5,10 \mathrm{mM} \mathrm{MgCl}$, $50 \mathrm{mM} \mathrm{NaCl}\left(30 \mathrm{~min}, 30^{\circ} \mathrm{C}\right)$. Proteins were heat inactivated $\left(65^{\circ} \mathrm{C}, 10 \mathrm{~min}\right)$ and plasmid-purified. The reaction mixture contained purified recombinant HbsU (100 nM); when needed (for testing substrate constructs); purified recombinant $\beta$-rec $(320 \mathrm{nM})$ was also added.

\section{Detection of SSR Products}

Genomic DNA was obtained by the Easy-DNA method (Invitrogen). In vitro $\beta$-rec/six RAGE reaction products were purified (QIAprep
Spin kit: Qiagen, Valencia CA, USA); $50 \mathrm{ng}$ were used for recombined substrate detection by PCR (Expand Long Template PCR system; Roche). When Recombiner plasmid was used as $\beta$-rec/six substrate, PCR was as described previously (27), and gave a specific $0.4 \mathrm{~kb}$ fragment. In vitro SSR products from the Lck-rec reporter construct were analyzed after SacII digestion; the nonrecombined plasmids generated four restriction fragments of $10,6.3,3.6$, and $2.7 \mathrm{~kb}$, whereas recombined plasmids generated the three latter fragments plus two specific (diagnostic) fragments $(9$ and $1 \mathrm{~kb})$.

\section{BioTechniques}

Connecting. Informing. Advancing. For 25 Years.

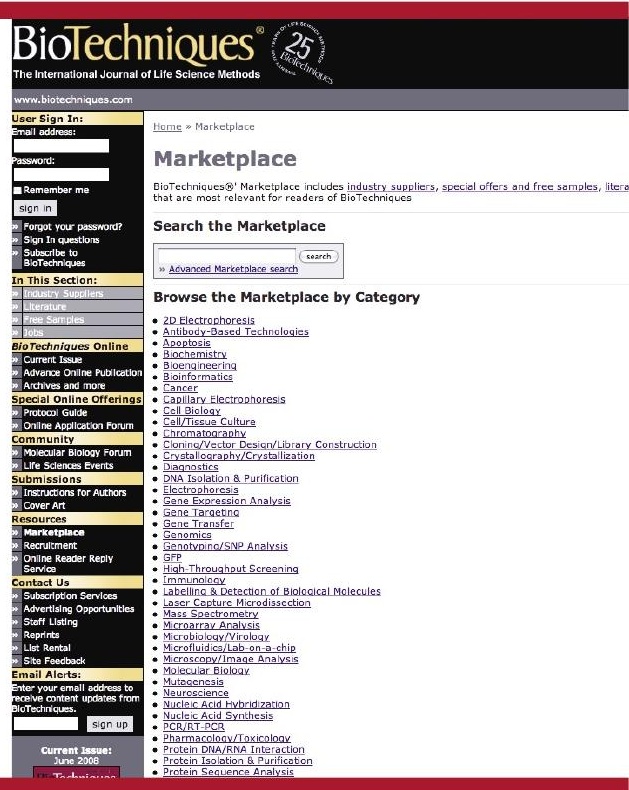

\section{Online Marketplace}

- Search industry suppliers

- Request commercial literature

- Browse special offers and free samples

Check out the BioTechniques Online Marketplace at www.biotechniques.com/marketplace 


\section{Research Reports}

For simultaneous detection of recombined $(1.6 \mathrm{~kb})$ and nonrecombined $(2.7 \mathrm{~kb})$ fragments, SSR products in genomic DNA from the Lck-rec reporter construct were detected by PCR using LCKp and LacZ-2 oligonucleotides $\left(93^{\circ} \mathrm{C}\right.$ for $2 \mathrm{~min} ; 35$ cycles of $94^{\circ} \mathrm{C}$ for $15 \mathrm{~s}, 57^{\circ} \mathrm{C}$ for $30 \mathrm{~s}, 68^{\circ} \mathrm{C}$ for $2 \mathrm{~min}$; $68^{\circ} \mathrm{C}$ for $7 \mathrm{~min}$ ).

In vitro and in vivo SSR products from the psixTCR $\beta$ construct were analyzed by PCR using the oligonucleotides TCRb1, NEO1, and TCRb2g $\left(95^{\circ} \mathrm{C}\right.$ for $2 \mathrm{~min}$; 35 cycles of $94^{\circ} \mathrm{C}$ for $30 \mathrm{~s}, 57^{\circ} \mathrm{C}$ for $30 \mathrm{~s}, 72^{\circ} \mathrm{C}$ for $2 \mathrm{~min}$; $72^{\circ} \mathrm{C}$ for $5 \mathrm{~min}$ ). Alleles were identified by the following PCR products: nonrecombined targeted locus (1.22 kb), WT nontargeted locus $(0.6 \mathrm{~kb})$, and recombined targeted locus $(0.3 \mathrm{~kb})$.

\section{Western Blot and Fluorescence Microscopy}

Total proteins were extracted from cell cultures or tissue samples (24), separated $(20 \mu \mathrm{g})$ by SDS-PAGE, and transferred to polyvinylidene fluoride (PVDF) membranes (ImmunobilonP, Millipore, Bedford, MA, USA). Antibodies were anti- $\beta$ recombinase (rabbit pAb, 1:500) (6), and HRP-labeled polyclonal goat antirabbit secondary (Dako, Glostrup, Denmark). Antibody binding was visualized by chemiluminescence (ECL Western Blot system; GE Healthcare).

EGFP and $\beta$-EGFP fusion protein expression in vivo was detected by fluorescence microscopy. The EGFP moiety was detected by direct fluorescence microscopy. For detection of $\beta$-rec, cells were fixed with $3 \%$ formaldehyde, 5\% Triton X-100 (20 min, room temperature), blocked, and stained with anti- $\beta$ recombinase (1:500; generated in-house) and Cy3goat anti-rabbit $\mathrm{IgG}\left(\mathrm{H}^{+} \mathrm{L}\right)$ antibody (1:400; GE Healthcare). Mounted samples were analyzed with a Leitz DMRB epifluorescence microscope (Leica Microsystems, Barcelona, Spain). Images were noise-filtered, background-corrected, and processed using Adobe Photoshop (Adobe Systems, San Jose, CA, USA).

\section{RESULTS}

\section{Generation of Transgenic Mice Expressing $\beta$ Recombinase at Early Stages of Thymic Development}

To test the in vivo function and efficiency of the $\beta$-rec/six system we followed a scheme similar to that used for Cre-loxP (29). We generated transgenic lines expressing $\beta$-rec in thymus; the $\beta$-rec coding sequence was placed under the control of the proximal Lck promoter (33). After transfer to the genome, $\beta$-rec activity in the resulting transgenic animals $(\mathrm{Tg} \beta$; Figure 1A) would mainly be restricted to immature $\mathrm{T}$ cell populations of adult thymus. After transgenesis, offspring were PCRscreened (not shown) and confirmed by Southern blot (Figure 1B). We established one line from each of the five selected founder mice (Figure 1B). Western blot identified two Lck- $\beta$ transgenic lines $(\operatorname{Tg} \beta 1$ and $\operatorname{Tg} \beta 2$ ) expressing high thymic $\beta$-rec levels; expression was much lower in spleen (Figure 1C). Neither line showed alterations in thymus, spleen, or peripheral blood cell populations (Supplementary Figure S1). $\beta$-rec was expressed in thymus as a single protein species $(25 \mathrm{kDa})$. To demonstrate intrinsic catalytic activity, we prepared crude thymus extracts from individual mice of each Lck- $\beta(\operatorname{Tg} \beta)$ transgenic line (see Primary Cell Suspensions section in Materials and Methods) and tested recombinase activity by the $\beta$-rec/six RAGE system (27). All mice showed thymic $\beta$-rec activity, as indicated by the expected $0.4 \mathrm{~kb}$ recombination-diagnostic band (Figure 1D). The Lck- $\beta$ transgenic line $\operatorname{Tg} \beta 2$ was used for further work, except where indicated.

\section{Tissue- and Site-specific $\beta$ Recombinase-mediated Recombination in Transgenic Mice}

To demonstrate the in vivo activity of the $\beta-\mathrm{rec} /$ six system, we developed an approach similar to that used initially for Cre-loxP, in which a $\beta$ galactosidase gene flanked by lox $\mathrm{P}$ sites (floxed) is in direct orientation under the control of the proximal Lck promoter (29). We generated the pLck-rec reporter construct (Figure 2A) harboring a sixed puromycin resistance gene $\left(\right.$ Puro $\left.^{R}\right)$ under the control of the proximal Lck promoter, followed by the $\beta$-galactosidase sequence; the genomic integrated version in the derived transgenic mice was denominated Tgrec. Deletion of the sixed-Puro ${ }^{\mathrm{R}}$ segment by $\beta$-rec would generate the recombined Tgrec $*$ structure, which should express $\beta$-galactosidase (Figure $2 \mathrm{~A})$. To test its suitability for in vivo analyses, we first evaluated pLck-rec as a $\beta$-rec substrate in vitro using the RAGE system; restriction analysis of the products showed efficient, sitespecific recombination (Figure 2B), indicated by the appearence of the diagnostic SacII restriction fragment (1 kb, indicated by $\mathrm{R})$. Transfection of the recombined plasmid into Jurkat cells confirmed $\beta$-galactosidase expression (Figure 2C). For in vivo analysis, we obtained two transgenic lines (Tgrec 1 and Tgrec2) from zygotes microinjected with pLck-rec (Figure 2D); Southern analysis confirmed transgene integrity and estimated copy number (15 and 3, respectively). Evaluation for transgene-associated phenotypes showed no differences in thymus cell subpopulations compared with WT counterparts (see thymic CD4 and CD8 cells, Figure 2E).

To confirm that the integrated $T$ grec reporter was a $\beta$-rec substrate, we transduced peripheral $\mathrm{T}$ cells from Tgrec mice with a retroviral vector encoding $\beta$-EGFP fusion protein $(\mathrm{pLZR}-\beta$-EGFP) or EGFP (pLZRCMV-EGFP) (23) (Figure 3A). After sorting the retrovirally transduced population (30.7\%; Figure 3A), immunofluorescence confirmed $\beta$ EGFP expression in FACS-purified transduced cells $\left(\mathrm{EGFP}^{+}\right)$(Figure $\left.3 \mathrm{~B}\right)$. Both transgenic lines showed $\beta$-recdependent SSR activity (Figure 3C) and were bred with the Lck- $\beta$ transgenic line $\operatorname{Tg} \beta 2$. Double hemizygote transgenic $\operatorname{Tg} \beta /$ Tgrec mice were obtained and showed no alterations in thymus or spleen lymphoid populations compared with single hemizygote Tgrec mice (not shown). 


\section{Research Reports}

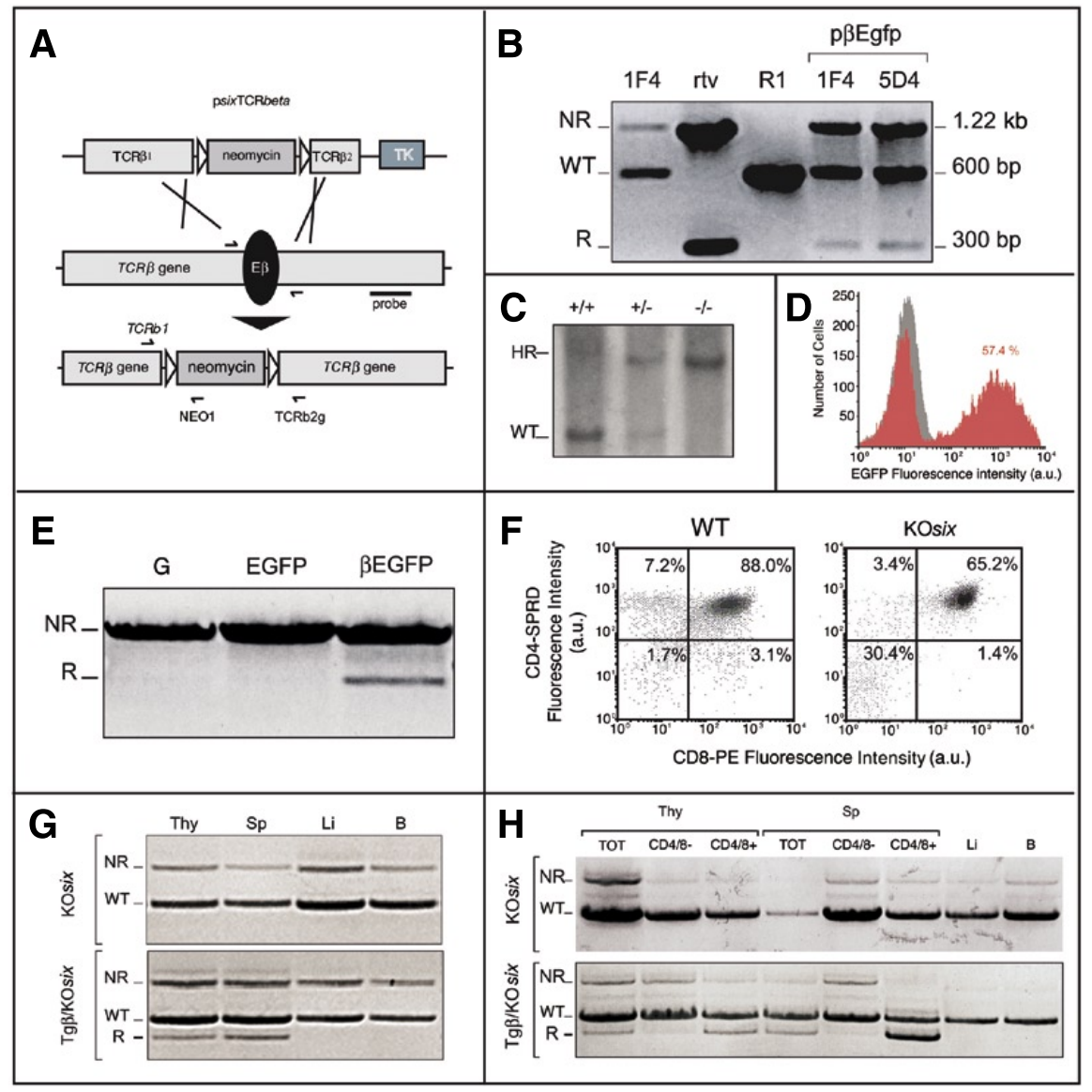

Figure 5. $\beta$-rec/six-dependent manipulation of single genomic loci. (A) Scheme of the psix-neosixTCR $\beta$ targeting vector ( $\mathrm{psixTCR} \beta$ ) in combination with the endogenous and homologously recombined TCR $\beta$ loci; the sixed neomycin resistance cassette (open triangles) was coupled with the $5^{\prime}$ and $3^{\prime}$ homology arms in the targeting vector. Positions of sequences used as oligonucleotide probes (TCRb1, $\mathrm{NEO} 1$, and TCRb2g) in PCR screenings are indicated (arrows), as is the probe used for Southern blot (bar). (B) PCR to detect SSR in homologously recombined embryonic stem cell clones (1F4 and 5D4) transfected with the p $\beta E G F P$ expression plasmid. Genomic DNA from untransfected 1F4 and wild-type ES cells ( $1 \mathrm{~F} 4$ and $\mathrm{R} 1$, respectively) and an in vitro recombined psixTCR $\beta$ plasmid (rtv) were included as controls. R, site-specific recombination (SSR)-derived $(0.3 \mathrm{~kb})$; NR, nonrecombined $(1.22 \mathrm{~kb})$ and WT, wild-type $(0.6 \mathrm{~kb})$ products. (C) Southern blot of genomic tail DNA from homozygous (-/-) and heterozygous (+/-) $\Delta$ Ebeta-six-neo-six ${ }^{-/-}($KOsix) mice compared with wild-type (+/+) mice. HR, recombinant allele (4.2 kb); WT, wild-type allele (3.0 kb). (D) Peripheral T cells from KOsix animals were obtained and transduced with the pLZR- $\beta$-EGFP retroviral vector to obtain expression of $\beta$-EGFP fusion protein, or with the pLZR-CMV-GFP control vector. The figure shows a representative FACS analysis of retrovirally transduced peripheral $\mathrm{T}$ cell populations (red) in comparison with the mock-transduced population (gray). a.u., arbitrary units. (E) Purified transduced cell populations $\left(\mathrm{EGFP}^{+}\right.$) were analyzed by PCR (see [B]) for simultaneous detection of the SSR-diagnostic (R; $0.3 \mathrm{~kb})$ and the nonrecombined (NR; $1.22 \mathrm{~kb})$ fragments. The figure shows the PCR results obtained with genomic DNA from tail $(\mathrm{G})$ or peripheral $\mathrm{T}$ cells transduced with either the pLZR-CMV-EGFP retroviral control vector (EGFP) or the pLZR$\beta$-EGFP retroviral vector ( $\beta$-EGFP). (F) Thymic, splenic, and peripheral blood cell subpopulations of homozygotic transgenic lines (KOsix) were studied by FACS to confirm E $\beta$ elimination. The example in the panel shows the differential representation of CD4/CD8 thymic subpopulations; numbers indicate the respective percentage contribution of each subpopulation in wild-type (left) and KOsix (right) animals. a.u., arbitrary units; WT, wild-type. (G) Genomic DNA was obtained from thymus (Thy), spleen (Sp), liver $(\mathrm{Li})$, and brain $(\mathrm{B})$ of either KOsix homozygotes or double transgenic $(\mathrm{Tg} \beta / \mathrm{KO}$ six) hemizygotes. The DNA was analyzed by PCR (see [B]) for simultaneous detection of the SSR diagnostic (R; $0.3 \mathrm{~kb})$, the nonrecombined (NR; $1.22 \mathrm{~kb}$ ) and the wild-type (WT; $0.6 \mathrm{~kb}$ ) allele-derived fragments. (H) Specific cell subpopulations of thymus (Thy) and spleen ( $\mathrm{Sp}$ ) were obtained either from KOsix homozygotes or double transgenic ( $\mathrm{Tg} \beta / \mathrm{KO}$ six) hemizygotes and analyzed by PCR as indicated in (B). TOT, total organ populations; CD4/8-, double-negative CD4-/CD8- cells; CD4/8+, cells expressing CD4, CD8, or both. Genomic DNA from liver (Li) and brain (B) was analyzed in parallel to confirm specificity of $\beta$-rec expression in the $\mathrm{Tg} \beta / \mathrm{KO}$ six mice.
Western blot of double hemizygotes showed that $\beta$-rec expression was high in thymus, lower in spleen and lymph nodes, and absent in liver and brain cells (Figure 4A). PCR concurred, showing recombination in thymus, spleen, and lymph node cells, but not in liver and brain or tissues from single Tgrec hemizygotes (Figure 4B). We also studied SSR in doublenegative (DN), single-positive (SP), and double-positive (DP) cell subsets from thymus and in $\mathrm{T}$ cells $\left(\mathrm{CD} 4^{+}\right.$or $\mathrm{CD}^{+}$) and other cells (CD4-/CD8) from spleen. Comparison of nonrecombined/recombined band intensities showed that specific SSR was maximal in $\mathrm{CD}^{+}$and $\mathrm{CD} 8+(\mathrm{SP}+\mathrm{DP})$ thymus and spleen cells (Figure 4C), indicating efficient SSR at the Tgrec substrate.

\section{Targeting a Single Predetermined Genomic Locus with the $\beta$-rec/six Model}

To evaluate $\beta$-rec/six activity at a specific locus, we used a targeting construct similar to that used by Bouvier et al. to demonstrate the critical role of the $T C R \beta$ transcriptional enhancer $(E \beta)$ in $\alpha \beta \mathrm{T}$ cell development (30), but with the loxP sites replaced by six sites (Figure 5A). In R1 129sv ES cells, E $\beta$ was replaced with neor flanked by six sites by homologous recombination of the psixTCR $\beta$ targeting vector. PCR and Southern blot indicated a recombined clone frequency of $\sim 1 / 100$ (Figure 5, B and C). Many positive clones (Figure 5B shows only clones $1 \mathrm{~F} 4$ and 5D4) were transfected with p $\beta E G F P$ to confirm that the genomeintegrated target sequence was a suitable $\beta$-rec substrate (Figure 5B). After transfection with p $\beta E G F P$, both clones were found to harbor the SSR diagnostic fragment $(\mathrm{R} ; 300$ $\mathrm{bp})$. Seven positive ES clones were selected and injected into host blastocysts; six chimeric mice were bred to generate heterozygous offspring carrying the $\mathrm{E} \beta$ replacement allele ( $\Delta$ Ebeta-six-neo-six ${ }^{+/-}$; abbreviated KOsix+/-). The recombination capacity of $\mathrm{KOsix}^{+/}$mouse peripheral $\mathrm{T}$ cells was confirmed by transducing them with pLZR- $\beta$-EGFP or pLZR-CMV- 


\section{Research Reports}

EGFP retroviral vectors (Figure 5, $\mathrm{D}$ and E). Homozygous mutants (KOsix) were obtained at the expected Mendelian frequency. The phenotype of adult mice was as described previously (30), including blockade of $\alpha \beta \mathrm{T}$ cell development at the DN cell stage (Figure 5F). Finally, KOsix mice were crossed with $\operatorname{Tg} \beta$ mice to generate $\mathrm{Tg} \beta /$ KO six mice. When compared with KOsix mice by immunofluorescence and Western blot analyses for $\beta$-rec expression, $\mathrm{Tg} \beta / \mathrm{KO}$ six mice were equivalent to $\mathrm{Tg} \beta / \mathrm{Tgrec}$ mice (not shown). Genomic PCR showed the expected $0.3 \mathrm{~kb}$ SSR band only in $\beta$-rec-expressing organs (thymus and spleen; not liver or brain) (Figure 5G). PCR analyses of SSR in thymic subsets and in spleen $\mathrm{T}$ and non- $\mathrm{T}$ cells isolated from $\mathrm{Tg} \beta / \mathrm{KO}$ six and KOsix mice indicated significant SSR activity in $\mathrm{CD}^{+}$and $\mathrm{CD}^{+}(\mathrm{DP}+\mathrm{SP})$ cells from thymus, spleen (Figure $5 \mathrm{H}$ ), and lymph nodes (not shown).

\section{DISCUSSION}

Technologies for site-specific recombination (SSR) have greatly broadened the possibilities for controlled genomic manipulation of living organisms. These systems permit strict spatio-temporal control of the desired manipulation, abrogating lethal effects due to systemic loss of a gene $(12,13)$ or bypassing developmental effects of unidentified redundant mechanisms that render undetectable phenotypes $(34,35)$.

The Cre-lox $\mathrm{P}$ system is the option of choice for introducing conditional modifications in animal models. The advantages of this system include high recombination efficiency in plants and animals, and simple machinery that requires only expression of the recombinase and a suitable substrate $(1,3,36)$. It is currently the most widely used SSR, despite characterization of others such as Flp/FRT from Saccharomyces cerevisiae $(20,37)$ and Int/attP from lambda phage (19). However, the eukaryotic genome contains cryptic lox $\mathrm{P}$ sites $(38,39)$ that can give rise to undesired genomic reorganization (40). Moreover, the need for spatio- temporal control of recombination at several loci has prompted a search for new SSR models $(1,14)$.

In contrast to the Int recombinase family, which includes Cre and Flp, the resolvo-invertase $\beta$-rec requires a host protein factor and a supercoiled substrate to catalyze resolution reactions (8). $\beta$-rec catalyzes exclusively intramolecular reactions $(31,32)$, that is, resolution or inversion, but not integration. Thus, since there is no risk of undesired interchromosomal rearrangements, this single SSR system could potentially be used to catalyze multiple recombination events in the same organism, eliminating the need for a specific system for each modification. We previously demonstrated that $\beta$ recombinase is active in eukaryotic cells, which implies that at least one eukaryotic factor can contribute to the recombination reaction, and that eukaryotic chromatin organization can provide the supercoiling needed for $\beta$-rec-mediated recombination (6). We also generated an inducible version of the $\beta$-rec/six system by fusing a hormone ligand binding domain to the $\beta$ recombinase $C$ terminus (24).

To study the feasibility and efficiency of the $\beta-\mathrm{rec} /$ six system in vivo, we have used strategies similar to those developed for the Cre-loxP system $(29,30)$. We generated the $\operatorname{Tg} \beta 1$ and $\operatorname{Tg} \beta 2$ mouse transgenic lines expressing $\beta$-rec in $\mathrm{T}$ cells, under the control of the proximal Lck promoter. We found no alterations in thymic cell subpopulations in either of the two $\operatorname{Tg} \beta$ lines (Supplementary Figure S1). $\beta$-rec is catalytically active and is expressed in thymus (Figure 1), spleen (Figures 1 and 4), and lymph nodes (Figure 4). Expression levels differed between $\operatorname{Tg} \beta$ lines, suggesting positional effects on the proximal Lck promoter. Although first described as specific for developing thymocytes (33), this promoter was later shown to be active at much lower levels in peripheral $\mathrm{T}$ cells $(41)$ and other tissues $(41,42)$. Transgene-specific positional effects have been suggested to explain some of the unexpected results (41). From our results, we conclude that $\beta$-rec can be expressed during $\mathrm{T}$ cell maturation and does not alter developmental programs.

To carry the target sequences, we generated the Tgrec and KOsix mouse lines; the former was obtained by conventional transgenesis of the Lck-rec reporter construct (Figure $2 \mathrm{~A}$ ), and the latter by targeted manipulation of the TCR $\beta$ gene transcriptional enhancer $(E \beta)$. This strategy was comparable to that used for the Cre-loxP system, with six replacing lox $\mathrm{P}$. The target sequences contained a sixed reporter gene $\left(\mathrm{Puro}^{\mathrm{R}}\right.$ or $\left.\mathrm{Neo}^{\mathrm{R}}\right)$. To evaluate the in vivo activity of the $\beta$-rec/six system, we bred double transgenic mice $(\mathrm{Tg} \beta / \mathrm{Tgrec}$ and $\operatorname{Tg} \beta /$ KOsix) and compared them with single hemizygote mice (Tgrec and KOsix). Results were equivalent in both mouse lines, with good correlation between $\beta$-rec expression levels and recombination efficiency. Some faint bands with a similar size to the recombined product appeared in Tgrec animals (Figures 3C and 4C). We do not have a clear explanation for this, but similar bands have been detected in previous experiments, and were found to be nonspecific $(4,27$, and data not shown).

Compared with previous descriptions of the in vivo expression pattern directed by the proximal Lck promoter $(29,33,41,42), \beta$-recmediated SSR was higher in more mature thymic cell populations (SP and DP) than in the immature DN subpopulation. In the same mice, $\beta$-rec-mediated SSR was higher in spleen than in thymus (Figure 5). As this was observed in all Lck- $\beta$ transgenic lines $(\operatorname{Tg} \beta)$, it is unlikely to be due only to positional effects; the $\beta$-rec ORF sequences might also influence the Lck promoter. Previous studies of $\beta$-rec-mediated SSR in single cells established that $\beta$-rec protein levels are a limiting factor, and a threshold must be reached for SSR detection (24). This, and the longer period of $\beta$-rec protein expression in more mature thymic and peripheral $\mathrm{T}$ cells, could explain the higher SSR in mature thymic and peripheral T cells.

The $\beta$-rec/six system also permits in vivo manipulation of plant 


\section{Research Reports}

genomes (43), indicating the broad applicability of this system. The $\beta$-rec sequence used here and in previous studies (alone or C-fused with EGFP) is the WT, unengineered sequence $(6,24,27)$. Modifications to optimize expression, intrinsic specific activity, and/or nuclear localization, combined with induction strategies $(11,24)$, could yield a more efficient $\beta$-rec/six SSR system for in vivo use, alone or in combination with other available SSR models.

\section{ACKNOWLEDGEMENTS}

M.G. and A.B. contributed equally to this work. We thank Pierre Ferrier and Konstantinos Anastassiadis for providing plasmids pGEM-E-560R-LNL and pAdapt.hrtTA-VP16-ARIRES-EGFP, respectively, and Luis Miguel Criado for help in generating mouse models. We also thank Coral
Bastos for secretarial assistance and Catherine Mark and Simon Bartlett for editorial support. This work was supported by the Spanish Ministry of Science and Technology/CICYT (SAF2005-0864), the Comunidad Autónoma de Madrid (P-BIO-03062006), and the Red de Terapia Celular del Instituto de Salud Carlos III (TerCel), to A.B.; V.D. and J.G.-C. received fellowships from the Spanish Ministry of Science and Technology, and M.G. was supported by a fellowship from the Comunidad Autonoma de Madrid and is currently funded by the Instituto de Salud Carlos III. The Department of Immunology and Oncology was founded and is supported by the Spanish National Research Council (CSIC) and by Pfizer. The CNIC is supported by the Spanish Ministry of Health and Consumer Affairs and the Pro-CNIC Foundation.

\section{COMPETING INTERESTS STATEMENT}

The authors declare no competing interests.

\section{REFERENCES}

1. Metzger, D. and R. Feil. 1999. Engineering the mouse genome by site-specific recombination. Curr. Opin. Biotechnol. 10:470-476.

2. Sauer, B. 1993. Manipulation of transgenes by site-specific recombination: use of Cre recombinase. Methods Enzymol. 225:890-900.

3. Sauer, B. 1994. Site-specific recombination: developments and applications. Curr. Opin. Biotechnol. 5:521-527.

4. Rice, P.A. 2005. Resolving integral questions in site-specific recombination. Nat. Struct. Mol. Biol. 12:641-643.

5. Smith, M.C. and H.M. Thorpe. 2002. Diversity in the serine recombinases. Mol. Microbiol. 44:299-307.

6. Diaz, V., F. Rojo, A.C. Martinez, J.C. Alonso, and A. Bernad. 1999. The prokaryotic beta-recombinase catalyzes site-specific recombination in mammalian cells. J. Biol. Chem. 274:6634-6640.

\section{More Procugtínty}

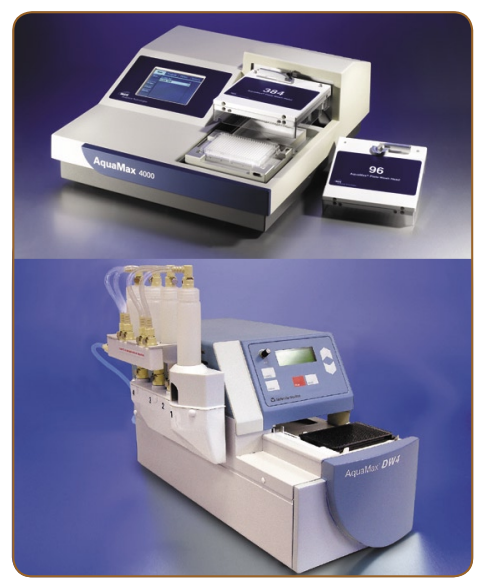

The flexible 96/384-well AquaMax 4000 washer (top) and integrated 96/384/1536-well AquaMax DW4 washer/ dispenser (bottom)
Run more assays in less time with the new AquaMax ${ }^{\circledR}$ series of washers and dispensers from MDS Analytical Technologies. With a unique modular design, the AquaMax systems can be easily configured to meet your current biochemical and cell-based application requirements, providing affordable upgrade options when your lab requirements change. The AquaMax 96-, 384-, and 1536-well heads are interchangeable and extend the capabilities of your washer and dispenser within a single instrument platform.
More Flexibility
$\Theta$ Configurable for $96-$, 384-, and 1536-well microplate formats
$\ominus$ Up to 4 fluid inlets for buffers and solutions allow multiple users without bottle changing
$\Theta$ Integrated stacker option for up to 50 microplates
More Reliability
$\ominus$ Precise aspiration and dispense control allow fast microplate processing
$\Theta$ Comprehensive, single-button, OneTouch cleaning, prime, and rinse utilities
$\Theta$ Stores up to 99 user-defined programs

Upgrade your liquid handling tools to increase your productivity. Call us for an on-site demonstration or visit www.moleculardevices.com/liquid for more information.

\section{Molecular Devices}

now part of MDS Analytical Technologies

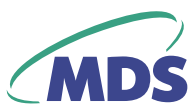




\section{Research Reports}

7. Rojo, F. and J.C. Alonso. 1995. The beta recombinase of plasmid pSM19035 binds to two adjacent sites, making different contacts at each of them. Nucleic Acids Res. 23:31813188.

8. Alonso, J.C., F. Weise, and F. Rojo. 1995 The Bacillussubtilis histone-like protein Hbsu is required for DNA resolution and DNA inversion mediated by the beta recombinase of plasmid pSM19035. J. Biol. Chem. 270:2938-2945.

9. Canosa, I., F. Rojo, and J.C. Alonso. 1996. Site-specific recombination by the beta protein from the streptococcal plasmid pSM19035: minimal recombination sequences and crossing over site. Nucleic Acids Res. 24:2712-2717.

10. Rojo, F., F. Weise, and J.C. Alonso. 1993. Purification of the beta product encoded by the streptococcus pyogenes plasmid pSM19035. A putative DNA recombinase required to resolve plasmid oligomers. FEBS Lett. 328:169-173.

11. Sorrell, D.A. and A.F. Kolb. 2005. Targeted modification of mammalian genomes. Biotechnol. Adv. 23:431-469.

12. Gu, H., J.D. Marth, P.C. Orban, H. Mossmann, and K. Rajewsky. 1994. Deletion of a DNA polymerase beta gene segment in $\mathrm{T}$ cells using cell type-specific gene targeting. Science 265:103-106.

13. Ioffe, E. and P. Stanley. 1994. Mice lacking $\mathrm{N}$-acetylglucosaminyltransferase I activity die at mid-gestation, revealing an essential role for complex or hybrid N-linked carbohydrates. Proc. Natl. Acad. Sci. USA 91:728732.

14. Rossant, J. and A. McMahon. 1999. "Cre"ating mouse mutants-a meeting review on conditional mouse genetics. Genes Dev. 13:142-145.

15. Agah, R., P.A. Frenkel, B.A. French, L.H. Michael, P.A. Overbeek, and M.D. Schneider. 1997. Gene recombination in postmitotic cells. Targeted expression of $\mathrm{Cre}$ recombinase provokes cardiac-restricted, sitespecific rearrangement in adult ventricular muscle in vivo. J. Clin. Invest. 100:169-179.

16. Barlow, C., M. Schroeder, J. LekstromHimes, H. Kylefjord, C.X. Deng, A. Wynshaw-Boris, B.M. Spiegelman, and K.G. Xanthopoulos. 1997. Targeted expression of Cre recombinase to adipose tissue of transgenic mice directs adipose-specific excision of loxP-flanked gene segments. Nucleic Acids Res. 25:2543-2545.

17. Chang, B.H., W. Liao, L. Li, M. Nakamuta, D. Mack, and L. Chan. 1999. Liver-specific inactivation of the abetalipoproteinemia gene completely abrogates very low density lipoprotein/low density lipoprotein production in a viable conditional knockout mouse. J. Biol. Chem. 274:6051-6055.

18. Utomo, A.R., A.Y. Nikitin, and W.H. Lee. 1999. Temporal, spatial, and cell type-specific control of Cre-mediated DNA recombination in transgenic mice. Nat. Biotechnol. 17:1091-1096.

19. Zubko, E., C. Scutt, and P. Meyer. 2000. Intrachromosomal recombination between attP regions as a tool to remove selectable marker genes from tobacco transgenes. Nat. Biotechnol. 18:442-445.

20. Awatramani, R., P. Soriano, C. Rodriguez, J.J. Mai, and S.M. Dymecki. 2003. Cryptic boundaries in roof plate and choroid plexus identified by intersectional gene activation. Nat. Genet. 35:70-75.

21. Chen, L. and S.L. Woo. 2005. Complete and persistent phenotypic correction of phenylketonuria in mice by site-specific genome integration of murine phenylalanine hydroxylase cDNA. Proc. Natl. Acad. Sci. USA 102:15581-15586.

22. Ginsburg, D.S. and M.P. Calos. 2005. Sitespecific integration with phiC31 integrase for prolonged expression of therapeutic genes. Adv. Genet. 54:179-187.

23. Lewandoski, M. 2001. Conditional control of gene expression in the mouse. Nat. Rev. Genet. 2:743-755.

24. Servert, P., J. Garcia-Castro, V. Diaz, D. Lucas, M.A. Gonzalez, A.C. Martinez, and A. Bernad. 2006. Inducible model for betasix-mediated site-specific recombination in mammalian cells. Nucleic Acids Res. 34:e1.

25. Meyers, E.N., M. Lewandoski, and G.R. Martin. 1998. An Fgf8 mutant allelic series generated by Cre- and Flp-mediated recombination. Nat. Genet. 18:136-141.

26. Murray, S.A., E.A. Carver, and T. Gridley. 2006. Generation of a Snail1 (Snai1) conditional null allele. Genesis 44:7-11.

27. Diaz, V., P. Servert, I. Prieto, M.A. Gonzalez, A.C. Martinez, J.C. Alonso, and A. Bernad. 2001. New insights into host factor requirements for prokaryotic beta-recombinase-mediated reactions in mammalian cells. J. Biol. Chem. 276:16257-16264.

28. Gagneten, S., Y. Le, J. Miller, and B. Sauer. 1997. Brief expression of a GFPcre fusion gene in embryonic stem cells allows rapid retrieval of site-specific genomic deletions. Nucleic Acids Res. 25:3326-3331.

29. Orban, P.C., D. Chui, and J.D. Marth. 1992. Tissue- and site-specific DNA recombination in transgenic mice. Proc. Natl. Acad. Sci. USA 89:6861-6865.

30. Bouvier, G., F. Watrin, M. Naspetti, C. Verthuy, P. Naquet, and P. Ferrier. 1996. Deletion of the mouse T-cell receptor beta gene enhancer blocks alphabeta T-cell development. Proc. Natl. Acad. Sci. USA 93:78777881.

31. Rojo, F. and J.C. Alonso. 1994. A novel site-specific recombinase encoded by the Streptococcus pyogenes plasmid pSM19035. J. Mol. Biol. 238:159-172.

32. Alonso, J.C., C. Gutierrez, and F. Rojo. 1995. The role of chromatin-associated protein Hbsu in beta-mediated DNA recombination is to facilitate the joining of distant recombination sites. Mol. Microbiol. 18:471478.

33. Wildin, R.S., A.M. Garvin, S. Pawar, D.B. Lewis, K.M. Abraham, K.A. Forbush, S.F. Ziegler, J.M. Allen, and R.M. Perlmutter. 1991. Developmental regulation of lck gene expression in T lymphocytes. J. Exp. Med. 173:383-393

34. Schorle, H., T. Holtschke, T. Hunig, A. Schimpl, and I. Horak. 1991. Development and function of $\mathrm{T}$ cells in mice rendered inter- leukin-2 deficient by gene targeting. Nature 352:621-624.

35. Kuhn, R., K. Rajewsky, and W. Muller. 1991. Generation and analysis of interleukin4 deficient mice. Science 254:707-710.

36. Sauer, B. and N. Henderson. 1988. Site-specific DNA recombination in mammalian cells by the Cre recombinase of bacteriophage $\mathrm{P} 1$. Proc. Natl. Acad. Sci. USA 85:5166-5170.

37. Dymecki, S.M. 1996. Flp recombinase promotes site-specific DNA recombination in embryonic stem cells and transgenic mice. Proc. Natl. Acad. Sci. USA 93:6191-6196.

38. Thyagarajan, B., M.J. Guimaraes, A.C. Groth, and M.P. Calos. 2000. Mammalian genomes contain active recombinase recognition sites. Gene 244:47-54.

39. Schmidt, E.E., D.S. Taylor, J.R. Prigge, S. Barnett, and M.R. Capecchi. 2000 Illegitimate Cre-dependent chromosome rearrangements in transgenic mouse spermatids. Proc. Natl. Acad. Sci. USA 97:13702-13707.

40. Loonstra, A., M. Vooijs, H.B. Beverloo, B.A. Allak, E. van Drunen, R. Kanaar, A. Berns, and J. Jonkers. 2001. Growth inhibition and DNA damage induced by Cre recombinase in mammalian cells. Proc. Natl. Acad. Sci. USA 98:9209-9214.

41. McGuire, E.A., C.E. Rintoul, G.M. Sclar, and S.J. Korsmeyer. 1992. Thymic overexpression of Ttg-1 in transgenic mice results in T-cell acute lymphoblastic leukemia/lymphoma. Mol. Cell. Biol. 12:4186-4196.

42. Omri, B., C. Blancher, B. Neron, M.C. Marty, J. Rutin, T.J. Molina, B. Pessac, and P. Crisanti. 1998. Retinal dysplasia in mice lacking p56lck. Oncogene 16:2351-2356

43. Gronlund, J.T., C. Stemmer, J. Lichota, T. Merkle, and K.D. Grasser. 2007 Functionality of the beta/six site-specific recombination system in tobacco and Arabidopsis: a novel tool for genetic engineering of plant genomes. Plant Mol. Biol. 63:545-556.

Received 20 December 2007; accepted 3 March 2008.

The present address for J.G.-C. is Banco Andaluz de Células Madre (BACM), Centro de Investigaciones Biomédicas, Avda. del Conocimiento s/n E-18100, Armilla, Granada, Spain.

Address correspondence to Antonio Bernad, Department of Regenerative Cardiology, Nacional de Investigaciones Cardiovasculares (CNIC), Melchor Fernández Almagro 3, E-28029, Madrid, Spain.e-mail: abernad@cnic.es

To purchase reprints of this article, contact: Reprints@BioTechniques.com 